\title{
Model for Assessment and Computational Analysis of the Concentration of Zinc Dissolved during Leaching of Sphalerite in Butanoic Acid Solution
}

\author{
C. I. Nwoye ${ }^{1 *}$, and I. E. Mbuka ${ }^{2}$ \\ ${ }^{1}$ Department of Metallurgical and Materials Engineering, Nnamdi Azikiwe University, Awka, \\ Anambra State, Nigeria. \\ ${ }^{2}$ Department of Metallurgical and Materials Engineering, Federal University of \\ Technology Owerri, Nigeria. \\ *Corresponding Author: chikeyn@yahoo.com
}

\section{ABSTRACT}

A model for assessment and computational analysis of the concentration of zinc dissolved during leaching of sphalerite in butanoic acid solution has been derived. The model

$$
Z n=\operatorname{Antilog}\left[(\exp (\gamma / \alpha))^{0.6173}\right]
$$

is dependent on the initial and final $\mathrm{pH}$ of the leaching solution. The validity of the model was found to be rooted in the expression $(\log Z n)^{1.62}=\exp (\gamma / \alpha)$ where both sides of the expression are approximately equal to 3. The maximum deviation of the model-predicted concentrations of dissolved zinc from that of the corresponding experimental values is less than $14 \%$ which is quite within the acceptable deviation limit of experimental results.

Keywords: Model, Dissolved Zinc, Sphalerite, Butanoic Acid Solution, Leaching.

\section{INTRODUCTION}

Sphalerite $(\mathrm{ZnS})$ is the most important zinc sulphide mineral and is the main source from which zinc is produced commercially. It exists naturally in association with other metal sulphide minerals, such as chalcopyrite $\left(\mathrm{CuFeS}_{2}\right)$, galena $(\mathrm{PbS})$, and Pyrite $\left(\mathrm{FeS}_{2}\right)$. In mineral processing engineering, the concentrates of these sulphide minerals are collected separately using selective conventional froth flotation. 
The conventional process of zinc recovery from sphalerite involves roasting to zinc oxide or sulphate, leaching the resultant calcine with dilute sulphuric acid and electrodepositing the zinc from the purified leach solution [1]. The roasting step produces $\mathrm{SO}_{2}$ gas, however environmental restriction imposed on sulphide smelters have resulted to the development of alternative methods including hydrometallurgical routes which eliminates production of $\mathrm{SO}_{2}$.

Various leaching studies have been carried out [2-7] using ammonia solution, nitric acid [8], hydrochloric acid [9-11], sulphuric acid [12,13] and oxidizing agents such as ferric ions [14-20].

Adebayo et al., [21] investigated the leaching of sphalerite with hydrogen peroxide and nitric acid solutions. The result of the investigation shows that leaching of sphalerite is dependent on temperature and stirring speed and inversely proportional to the ore size. The activation energy was found to be $28 \mathrm{kJmol}-1$ suggesting that the reaction is chemically controlled at the surface of the particle.

Olubambi et al. [22] carried out investigation on the effectiveness of hydrogen peroxide as an oxidant for the sulphuric acid leaching of zinc and copper from a complex sulphide ore. The result of the investigation indicates that the concentrations of zinc and copper decreased while silica, sulphur, iron and lead contents increased. Dissolution results [22] show that leaching rate of copper was lower than that of zinc. The highest recoveries of zinc and copper were obtained at a leaching time of 180 minutes, stirring speed of $160 \mathrm{rpm}$, ore particle size of $75 \mu \mathrm{m}$ and a concentration of $1 \mathrm{M} \mathrm{H}_{2} \mathrm{SO}_{4} / 1 \mathrm{M} \mathrm{H}_{2} \mathrm{O}_{2}$. It was observed that the leaching rate of zinc and copper increased with increasing hydrogen peroxide concentration while increased stirring speed had a negative leaching effect as it promotes hydrogen peroxide decomposition [22].

Nwoye [23] derived a model for predicting the initial solution $\mathrm{pH}$ at pre-assumed final $\mathrm{pH}$ and concentration of dissolved zinc, during leaching of galena in butanoic acid solution. The model

$$
\alpha=\left(\frac{1.4 \gamma}{\ln \left[(\mathrm{Zn})^{1 / 3}\right]}\right)
$$

shows that the initial $\mathrm{pH}$ of the leaching is dependent on the values of the pre-assumed final solution $\mathrm{pH}$ and concentration of dissolved zinc. The validity of the model was rooted in the expression $\mathrm{e}^{\mathrm{N}(\gamma / \alpha)}={ }^{3} \sqrt{\mathrm{Zn}}$ where both sides of the expression were approximately equal to 4 . The respective deviation of the model-predicted initial solution $\mathrm{pH}$ value from that of the corresponding experimental value was less than $2 \%$ which is quite within the acceptable deviation limit of experimental results. 


\section{MODEL}

During the leaching process, the ore was assumed to be stationary in the reaction vessel and contains the un-leached lead and zinc as part of reaction remnants. The ore was attacked by hydrogen ions from butanoic acid within the liquid phase, and in the presence of oxygen.

\subsection{Model Formulation}

Results from experimental work [24] carried out at SynchroWell Research Laboratory, Enugu were used for the model derivation. These results are as presented in Table 1.

Computational analysis of these experimental results [24] shown in Table 1, resulted to Table 2 which indicate that;

$$
(\log \mathrm{Zn})^{\mathrm{N}}=\exp (\gamma / \alpha) \quad(\text { approximately) }
$$

Introducing the value of $\mathrm{Z}$ into equation (2)

$$
(\log \mathrm{Zn})^{1.62}=\exp (\gamma / \alpha)
$$

Multiplying the indices of both sides of equation (3) by $1 / 1.62$ reduces it to;

$$
\begin{aligned}
\log \mathrm{Zn} & =(\exp (\gamma / \alpha))^{1 / 1.62} \\
\log \mathrm{Zn} & =\left[(\exp (\gamma / \alpha))^{0.6173}\right] \\
\mathrm{Zn} & =\text { Antilog }\left[(\exp (\gamma / \alpha))^{0.6173}\right]
\end{aligned}
$$

$\mathrm{N}=1.62$ (Dissolution coefficient of zinc in butanoic acid) determined in the experiment [24].

$\alpha=$ Initial $\mathrm{pH}$ of the butanoic acid leaching solution just before the leaching process started.

$\gamma=$ Final $\mathrm{pH}$ of the butanoic acid leaching solution at time $\mathrm{t}$.

$\mathrm{Zn}=$ Concentration of dissolved $\mathrm{Zn}$ during the leaching process $(\mathrm{mg} / \mathrm{kg})$

Equation (6) is the derived model. 
Table 1. Variation of the initial and final $\mathrm{pH}$ of the butanoic acid leaching solution with the concentration of dissolved Zinc [24].

\begin{tabular}{|c|c|c|}
\hline$(\gamma)$ & $(\alpha)$ & $\mathrm{Zn}(\mathrm{mg} / \mathrm{kg})$ \\
\hline 3.98 & 3.80 & 79.96 \\
4.25 & 4.08 & 77.34 \\
4.33 & 4.24 & 72.24 \\
4.41 & 4.36 & 72.02 \\
4.50 & 4.46 & 71.96 \\
4.63 & 4.60 & 68.64 \\
4.84 & 4.81 & 64.42 \\
4.86 & 4.83 & 64.22 \\
\hline
\end{tabular}

\section{BOUNDARY AND INITIAL CONDITION}

Iron oxide ore was placed in cylindrical flask $30 \mathrm{~cm}$ high containing leaching solution of hydrogen peroxide. The leaching solution is non flowing (stationary). Before the start of the leaching process, the flask was assumed to be initially free of attached bacteria and other micro organism. Initially, the effect of oxygen on the process was assumed to be atmospheric. In all cases, weight of iron oxide ore used was $5 \mathrm{~g}$. The initial $\mathrm{pH}$ range of leaching solutions used; 3.80-4.83 and leaching time of $2 \mathrm{hrs}$ (120 minutes) were used for all samples. A constant leaching temperature of $25^{\circ} \mathrm{C}$ was used. Butanoic acid concentration at $0.27 \mathrm{~mol} /$ litre and average ore grain size of $150 \mu \mathrm{m}$ were also used. Details of the experimental technique are as presented in the report [24].

The leaching process boundary conditions include: atmospheric levels of oxygen (considering that the cylinder was open at the top) at both the top and bottom of the ore particles in the gas and liquid phases respectively. A zero gradient was assumed for the liquid scalar at the bottom of the particles and for the gas phase at the top of the particles. The sides of the particles were assumed to be symmetries.

\section{MODEL VALIDATION}

The formulated model was validated by calculating the deviation of model-predicted concentration of dissolved zinc from the corresponding experimental values. The deviation recorded is believed to be due to the fact that the surface properties of the ore and the physiochemical interactions between the ore and leaching solution which were found to play vital roles during the leaching process [24] were not considered during the model formulation. It 
is expected that introduction of correction factor to the predicted concentration of dissolved zinc, gives exactly the corresponding experimental values.

Deviation (De) (\%) of model-predicted initial $\mathrm{pH}$ values from those of the experiment is given by

$$
\mathrm{De}=\left(\frac{\mathrm{m}_{\mathrm{I}}-\mathrm{e}_{\mathrm{I}}}{\mathrm{e}_{\mathrm{I}}}\right) \times 100
$$

Where $\quad \mathrm{m}_{\mathrm{I}}=$ Model-predicted initial $\mathrm{pH}$ values

$\mathrm{e}_{\mathrm{I}}=$ Experimental initial $\mathrm{pH}$ values

Since correction factor $(\mathrm{Cr})$ is the negative of the deviation,

$\mathrm{Cr}=-\mathrm{De}$

Substituting equation (7) into equation (8) for De,

$\mathrm{Cr}=-100\left(\frac{\mathrm{m}_{\mathrm{I}}-\mathrm{e}_{\mathrm{I}}}{\mathrm{e}_{\mathrm{I}}}\right)$

It was observed that addition of the corresponding values of $\mathrm{Cr}$ from equation (9) to the modelpredicted initial $\mathrm{pH}$ gave exactly the corresponding experimental initial $\mathrm{pH}$ values [24].

\section{RESULTS AND DISCUSSION}

Computational analysis of these experimental results [24] shown in Table 1, resulted to Table 2 .

Table 2. Variation of $\exp (\gamma / \alpha)$ with $(\log Z n)^{1.62}$

\begin{tabular}{|c|c|c|c|}
\hline$(\gamma / \alpha)$ & $\exp (\gamma / \alpha)$ & $\log \mathrm{Zn}$ & (Log Zn) $^{1.62}$ \\
\hline 1.0474 & 2.8502 & 1.9029 & 2.8357 \\
1.0417 & 2.8340 & 1.8884 & 2.8007 \\
1.0212 & 2.7765 & 1.8588 & 2.7300 \\
1.0115 & 2.7497 & 1.8575 & 2.7269 \\
1.0090 & 2.7429 & 1.8571 & 2.7259 \\
1.0065 & 2.7360 & 1.8366 & 2.6773 \\
1.0062 & 2.7352 & 1.8090 & 2.6125 \\
1.0062 & 2.7352 & 1.8077 & 2.6094 \\
\hline
\end{tabular}


The derived model is equation (6). An ideal comparison of the initial $\mathrm{pH}$ as obtained from experiment and as predicted by the model for the purpose of testing the validity of the model is achieved by considering the $\mathrm{R}^{2}$ values (coefficient of determination). The values of the correlation coefficient, $\mathrm{R}$ calculated from the equation;

$$
R=\sqrt{ } R^{2}
$$

using the r-squared values (coefficient of determination) from Figs.1, 2 and Figs. 3, 4 show very close correlations; (0.9835),(0.9807) and (0.9129),(0.8738) between experimental and modelpredicted data respectively. This suggests proximate agreement between experimental and model-predicted concentrations of dissolved zinc.

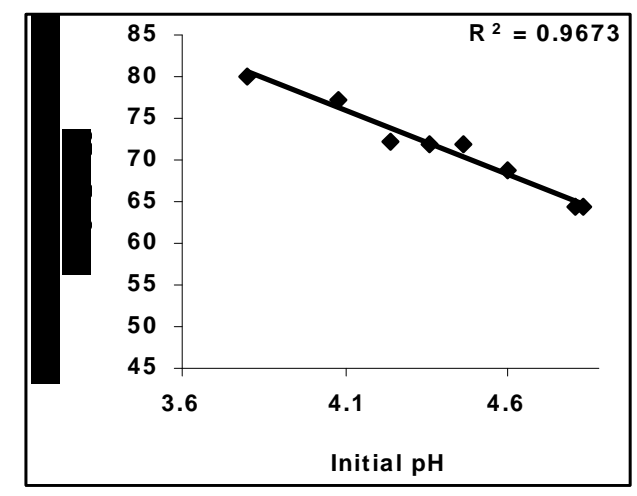

Fig. 1. Effect of initial solution $\mathrm{pH}$ on the concentration of zinc dissolved during butanoic acid leaching of sphalerite (as obtained from the experiment [24]).

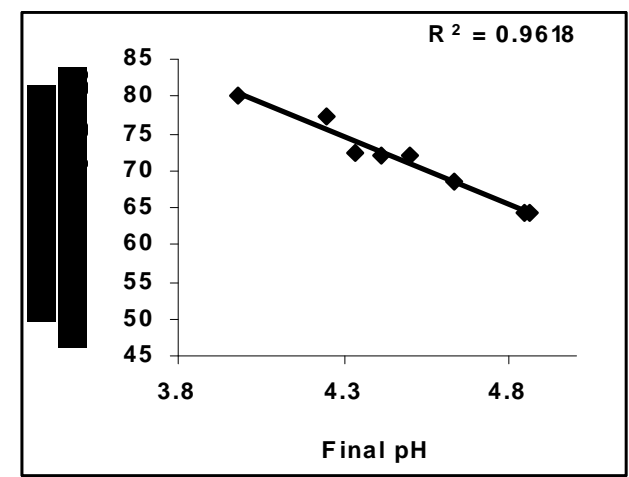

Fig. 2. Effect of final solution $\mathrm{pH}$ on the concentration of zinc dissolved during butanoic acid leaching of sphalerite (as obtained from the experiment [24]). 


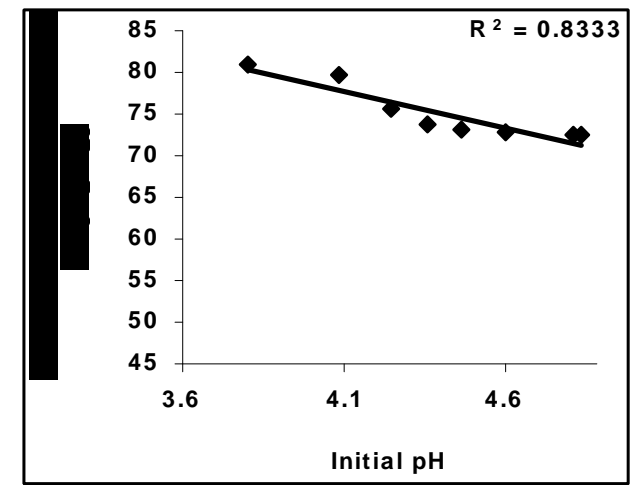

Fig. 3. Effect of initial solution $\mathrm{pH}$ on the concentration of zinc dissolved during butanoic acid leaching of sphalerite (as predicted by derived model).

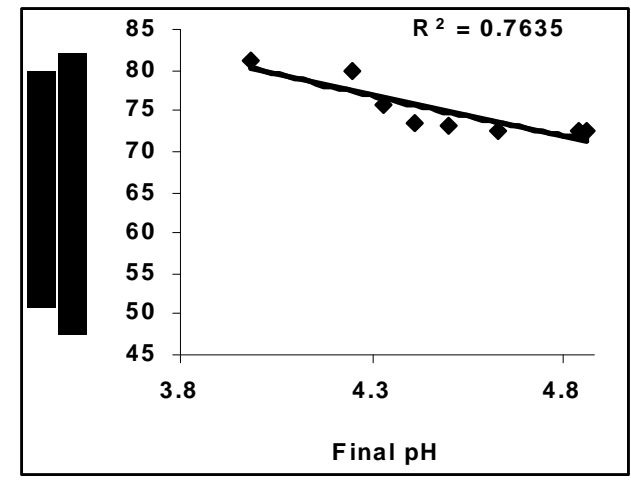

Fig. 4. Effect of final solution $\mathrm{pH}$ on the concentration of zinc dissolved during butanoic acid leaching of sphalerite (as predicted by derived model).

Figs. 5 and 6 show very close alignment of the curves from model-predicted concentrations of dissolved zinc (MoD) and that from the corresponding experimental values (ExD). The degree of alignment of these curves is indicative of the proximate agreement between both experimental and model-predicted concentration of dissolved zinc. The validity of the model is believed to be rooted on the expression $(\log \mathrm{Zn})^{1.62}=\exp (\gamma / \alpha)$ where both sides of the equation are approximately equal to 3. Table 2 also agrees with equation (2) following the values of (Log $\mathrm{Zn})^{1.62}$ and $\exp (\gamma / \alpha)$ evaluated following statistical and computational analysis carried out on the experimental results in Table1. Based on the foregoing, the model is believed to be very valid as a predictive tool. 


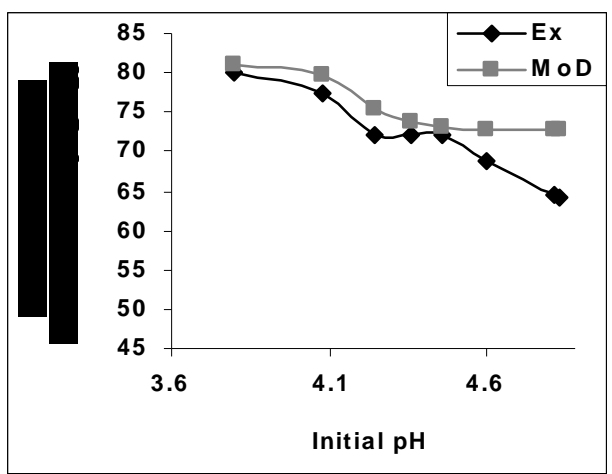

Fig. 5. Comparison of the concentrations of dissolved zinc relative to the initial solution $\mathrm{pH}$ as obtained from experiment [24] and derived model.

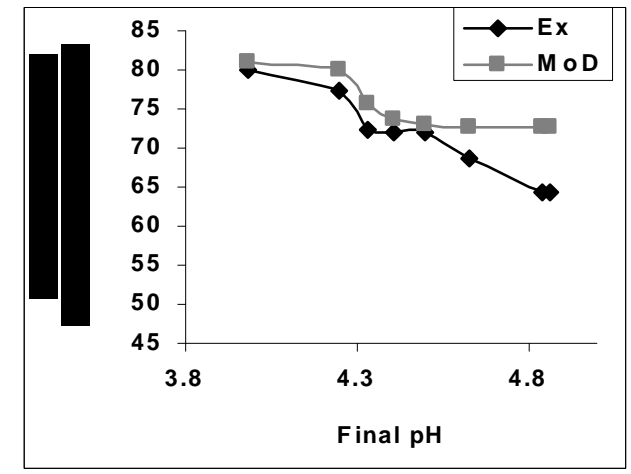

Fig. 6. Comparison of the concentrations of dissolved zinc relative to the final solution $\mathrm{pH}$ as obtained from experiment [24] and derived model.

Table 3 shows insignificant positive and negative deviations of the model-predicted concentration of dissolved zinc from the corresponding experimental values, which were less than $14 \%$, hence quite within the acceptable deviation limit of experimental results. The least and highest magnitude of deviation of the model-predicted concentration of dissolved zinc (from the corresponding experimental values) are $+1.41 \%$ and $+13.08 \%$. 
Table 3. Variation of deviation of model-predicted concentration of dissolved zinc with associated correction factor.

\begin{tabular}{|c|c|}
\hline De (\%) & Cr (\%) \\
\hline+1.41 & -1.41 \\
+3.23 & -3.23 \\
+4.61 & -4.61 \\
+2.25 & -2.25 \\
+1.67 & -1.67 \\
+5.87 & -5.87 \\
+12.73 & -12.73 \\
+13.08 & -13.08 \\
\hline
\end{tabular}

These corresponds to initial and final solution $\mathrm{pH} 3.80 \& 4.83$ and $3.98 \& 4.86$ respectively. Correction factors to the model-predicted concentrations of dissolved zinc indicate similar values as in the deviation but of opposite sign. This is because correction factor is the negative of the deviation as shown in eqns. (8) and (9). It is believed that the correction factor takes care of the effects of the surface properties of the ore and the physiochemical interaction between the ore and the leaching solution which (affected experimental results) were not considered during the model formulation. Based on the foregoing, Table 3 indicates that a correction factor of -1.41 and $-13.08 \%$ make up for the least and highest deviation of +1.41 and $+13.08 \%$ resulting from application of initial solution $\mathrm{pH} 3.80$ and 4.83. It is pertinent to state that the actual deviations are just the modulus of the values. The role of the sign attached to the values is just to show when the deviation is surplus or deficit.

\section{CONCLUSION}

The model assesses and computes the concentration of zinc dissolved (relative to known values of the initial and final solution $\mathrm{pH}$ ) during leaching of Ishiagu (Nigeria) sphalerite in butanoic acid solution. The validity of the model is believed to be rooted in the expression $(\log \mathrm{Zn})^{1.62}=$ $\exp (\gamma / \alpha)$ where both sides of the expression are approximately equal to 3 . The maximum deviation of the model-predicted concentrations of dissolved zinc from that of the corresponding experimental values is less than $14 \%$ which is quite within the acceptable deviation limit of experimental results. 


\section{ACKNOWLEDGEMENT}

The author thanks Dr. Ekeme Udoh and Pearl Bassey, modelling experts at Linkwell Modelling Centre Calabar for his technical inputs. The management of SynchroWell Nig. Ltd. Enugu is also appreciated for permitting and providing the experimental data used in this work.

\section{REFERENCES}

[1] Bogue, R.G., Reynolds, R.R. (1951) Report on the Lead-Zinc Deposits of the Abakiliki District Ogoja Province, Nigeria (unpublished manuscripts).

[2] Udum, J.T., (1998) Beneficiation Studies of Ishiagu Pb - Zn ore Trans SME/AIME 24(1): 500

[3] Okoro, C.C. (2004) Hydrometallurgical Extraction of Lead from Ishiagu Galena, B. Eng. Project Materials and Metallurgical Engineering Dept., Federal University of Technology Owerri.

[4] Onyemaobi, O. O.(1990) Evaluation of Flotation Performance of Nigeria's Sphalente (ZnS) Without Activation by copper. Ife Journal of Tech. 2(2):21-25.

[5] Onyemaobi, O.O. Anyakwo, C.N. (1996) Factors Affecting the Performance of Nigeria's Lead and Zinc Ores for Industrial Usage JSET, 3(1): 46.

[6] Onyemaobi, O.O. (1990) Flotability of Ishiagu Galena as Raw Materials for Smelters. Nigeria Journal of Applied Science 8 (1): 93-101.

[7] Agha, U.H. (1990) Role of PH on Flotation of Sphalerite from Ishiagu Lead-Zinc Ore, Nigeran Journal of Applied Science 2 (2):4-6.

[8] Olubambi, P.A, Ndlovu, S., Potgieter, H., Borode, J.O. (2007) Effects of Ore Mineralogy on the Microbial Leaching of Low Grade Complex Sulphide Ore. Hydrometallurgy 86: 96-104.

[9] Olubami, P.A., Borode, J.O., Ndlovu, S. (2006) Sulphuric Acid Leaching of Zinc and Copper from Nigerian Complex Sulphide Ore in the Presence of Hydrogen Peroxide. Journal of the Southern African Inst. Of Mining and Metallurgy 106: 765-769.

[10] Nwoye, C. I. (2008) Ph.D Thesis, Metallurgical and Materials Engineering Department, Federal University of Technology, Owerri,178.

[11] Haver, F.P., Wong, M. M. (1971) Recovering Elemental Sulfur from Non-Ferrous Minerals. Rep.Invest. U.S Bur. Mines 7474,20 in Orlowska L and Golab B; Microbial Leaching of Blende Flotation Concentrate using Acidithiobacillus Ferrooxidans and Acidithiobacillus Thiooxidans Physicochemical Problems of Mineral processing 37,1990,58.

[12] Sklodowska, R. (1990) Microbial Leaching of Blende Flotation Concentrate using Acidithiobacillus Ferrooxidans and Acidithiobacillus Thiooxidans; Physico Chemical Problems of Mineral Processing 37:58.

[13] Cwalina, W. (1994) Microbial Leaching of Blende Flotation Concentrate using 
Acidithiobacillus Ferrooxidans and Acidthiobacillus Thiooxidans Physicochemical Problems of Mineral Processing 37:58.

[14] Makita, M., Esperon, M., Pereyra, B., Lopez, A., Orrantia, E. (2004) Reduction of Arsenic Content in a Complex Galena Concentrate by Acidithiobacillus Ferrooxidans; BioMed Central Biotechnology, 4:22 doi: 10.1186/1472-6750-6750-4-22 (published on line)

[15] Williamson, S., Rimstidt, M., Smith, T., Schumate, H. (2005) Rates of Leaching in Single and Two Phase System. Min. mag., 3

[16] Prosper, I. (2005) Acid leaching of lead sulphide, J. Med. Central. 3(4):13-16.

[17] Rawlings, D.E. (2005) Characteristics and Adaptability of Iron and Sulphur Oxidizing Microorganisms Used for the Recovery of Metals from Minerals and Their Concentrates, Bio Med Central, 4:13 doi 10:1186/1475-2859-4-13 (published on line)

[18] Dutrizac, J.E. (1986) The Dissolution of Galena in Ferric Chloride Media, Metallurgical Transactions B, 17B: 77.

[19] Seon-Hyo, K. K., Henein, H., Warren, G.W (1986) An Investigation of the Thermodynamics and Kinetics of the Ferric Chloride Brine Leaching of Galena Concentrate. Metallurgical Transaction B, 17B:26.

[20] Dix, R.B., Hendrix, J. L. (1986) Kinetics of $\mathrm{Cl}_{2}-\mathrm{O}_{2}$ Leaching of Lead-Zinc Flotation Concentrates. University of Nevada Reno, 89557

[21] Pinches, A. (1975) Bacterial Leaching of an Arsenic Bearing Sulphide Concentrate. The Institute of Mining and Metallurgy, England, 34.

[22] Nwoye, C. I. (2008) SynchroWell Research Work Report, DFM Unit, No 2008600, 15-28. [23] Nwoye, C. I. (2009) Model for Predicting the Initial Solution $\mathrm{pH}$ at Pre-Assumed Final pH and Concentration of Dissolved Zinc during Leaching of Galena in Butanoic Acid Solution. Journal of Minerals, Material Characterization \& Engineering,8(8):621-633.

[24] Nwoye, C. I. (2006) SynchroWell Research Work Report, DFM Unit, No 20061103, 56-64. 